\title{
Direito e educação em estado de exceção
}

\author{
Carta de Carolina Catini ${ }^{1}$
}

Resumo: Neste texto em formato de carta, a autora faz uma análise da educação capitalista, enfatizando a mudança na função social da educação massiva ao longo do processo histórico. A autora relaciona as transformações sofridas pela educação formal às mudanças na forma de realização dos direitos sociais e da força de trabalho como mercadoria. A reflexão contida na carta, sobre as bases que foram criadas para sujeitar a educação à uma forma específica de controle por parte de grandes conglomerados empresariais, indaga sobre a necessidade de a educação tornar-se um objeto de crítica da economia política. A partir da teoria marxiana, a autora examina a complexa conjuntura atual e os impactos do crescente conservadorismo, que se materializa no aumento do controle militar, religioso e empresarial da educação formal e não formal, modificando significativamente a estrutura educacional e alterando suas práticas e suas relações. De modo que a intenção da carta é chamar atenção para a subordinação e controle do trabalho educativos aos ditames de conglomerados empresariais, através do ajuste do serviço estatal à lógica de gestão empresarial.

Palavras-chave: Educação; Mercadoria; Economia-política.

${ }^{1}$ Professora da Faculdade de Educação da Universidade Estadual de Campinas. 
Campinas, setembro de 2018.

\section{Meu Caro Marx,}

Como seria bom poder contar agora com as suas armas da crítica! Tão propriamente vorazes e contundentes quanto necessitamos para retirar a análise da educação capitalista de seu persistente véu ideológico. Uma posição tão sui generis como a sua sobre as contradições deste momento histórico, tal qual as vivenciamos na periferia do capitalismo, movimentaria nossa capacidade de reflexão para a crítica e para a militância.

Sem dúvida, sabemos que "a arma da crítica não pode substituir a crítica das armas", e que continua valendo a sua formulação de que só poderemos derrotar o poder material que nos domina hoje com um poder material nosso. Mas o fato é que, por ora, parece estarmos distantes de construirmos esse poder e, assim também, de uma correspondente teoria crítica e revolucionária que emanada de nosso processo de luta e organização, sirva-lhe de alimento. Tanto porque são frágeis, neste momento, quaisquer manifestações de "conjunto", tamanha individuação, exploração, reificação e atomização das forças do trabalho, quanto porque a radicalidade do pensamento enfrenta a difícil tarefa de agarrar uma raiz que se encontra num terreno pantanoso de formas sociais que se transformam no solo da história.

Falar em raiz num "solo da história" até parece épico diante da efemeridade de nossas relações atuais. Mas em tempos de excesso de comunicação destituída de seus fins comunicativos, um certo desajuste na linguagem pode ser útil para manter o desassossego. Procurar saber o que segue conosco no curso da história não é algo ajustável à validade instantânea e espetacular dessa forma publicitária mediada pela tecnologia que invade como maremoto as relações pessoais e também a educação dominante. Assim como a aparência de autonomia é uma falsificação das correntes invisíveis que nos prendem cada vez 
mais firmemente à exploração, também a efemeridade, a precariedade, a intermitência das relações que vivenciamos de maneira violenta são formas de manifestação do sólido e duradouro antagonismo que se desdobra historicamente no núcleo deste nosso modo de vida: a contradição entre capital e trabalho.

Mas é evidente que te escrevo porque tenho muitas dúvidas e gostaria de saber tua opinião sobre questões que se impõe no presente. A única conviç̧ão que tenho é de que, para capturar o que importa nesses nossos tempos de "terra em transe", parece ser necessário aderir à uma forma que está em baixa. Pois não se trata de fazer propaganda, de convencer, de ganhar seguidores ou adeptos para uma forma de pensar, uma corrente teórica, de tentar vencer algum inimigo ideológico pela retórica, etc., senão de provocar uma discussão, um exercício de pensamento, uma abertura necessária para aprofundar a crítica.

A questão é a seguinte: acho que estamos assistindo à mais radical transformação que a educação já passou em sua história desde a generalização de sua forma social massiva e hegemônica, a escola. É urgente que a educação se torne objeto de uma minuciosa crítica da economia política! E, por conseguinte, da crítica do reformismo, uma vez que essa transformação está vinculada às mudanças na forma de realização dos direitos sociais e da força de trabalho como mercadoria. No caso dos chamados serviços públicos ou estatais, vemos que a realização da força de trabalho por meio de contratos intermitentes corresponde a direitos igualmente intermitentes, submetidos à lógica concorrencial, organizados privadamente por organizações que prestam os serviços que o Estado terceiriza. Refere-se, portanto, às relações entre trabalho e educação - tanto ao trabalho educativo, quanto à formação voltada para o trabalho, este que tem se realizado sob novas formas de precarização.

Os direitos sociais, que sempre representaram uma categoria tensa entre as necessidades materiais de quem vive do trabalho e as necessidades de quem os concede, apresentam hoje novas contradições 
ao desenvolver-se sob formas híbridas, articulando elementos do direito público e do direito privado. Por ligar diretamente necessidades materiais dos trabalhadores com prestação de serviços de grupos privados, coloca outros limites à perspectiva reformista, que age de modo mais ou menos relevante sobre os efeitos da desigualdade capitalista, mas nunca sobre suas bases. E, no entanto, em tempos de tão rebaixadas expectativas históricas de transformação radical, de tantas consequências da crise econômica, do desemprego, da precarização, da privação de serviços básicos, de cortes de gastos públicos, etc., a luta por direitos sociais adquire uma aura de positividade, como se estivesse livre de suas contradições imanentes. Essa reivindicação ganhou tal centralidade, como se pudesse responder às nossas necessidades atuais, como se os direitos sociais fossem simplesmente o contrário da privatização de tudo, e o Estado meramente o contrário do capital. A referida centralidade é tanto mais exacerbada quanto mais apareça cindida de práticas sociais que gerem formas de vida anticapitalistas, assumindo a posição de ser uma finalidade da luta e não um meio, como a concebe a tradição revolucionária e antirreformista.

Caro Marx, imagine que, num país como o Brasil, no qual se tardou tanto para que a educação alargasse seu alcance ao conjunto dos trabalhadores e trabalhadoras e seus filhos e filhas, é possível dizer que estão criadas as bases para uma sujeição da educação, tanto das redes estatais quanto privadas, à uma forma específica de controle por parte de fundos de investimentos, bancos, corporações, enfim, grandes conglomerados empresariais. Por certo não é de hoje que a educação pode ser mercantilizada, e constitui um ramo dos negócios, tanto quanto a fábrica de salsicha à qual você a igualava no célebre capítulo XIV do primeiro volume de O Capital (MARX, 2013). A novidade, fruto de modificações da forma social da educação, consiste em que ela se tornou, por assim dizer, um ativo financeiro da indústria de serviços educativos, e circula nas bolsas de valores, nas operações comerciais, nos títulos da dívida pública. Ela se converteu em um mercado cativo, com lucros garantidos pelo Estado, de modo que empresas, indústrias, 
bancos e suas fundações e institutos que desenvolvem os seus "trabalhos sociais" - colhendo os frutos do marketing e da renúncia fiscal - não agem apenas influenciando, ditando as regras, dando as cartas de políticas públicas, mas também trabalham efetivamente no controle, na gestão e na organização de setores de escolas, diretorias e até secretarias de ensino. Diretamente, com emprego de força de trabalho vivo que as próprias empresas mobilizam por meio das terceirizações e prestações de serviços, ou indiretamente, empurrando goela abaixo seus "métodos" e seus produtos de "inovação", que ao chegarem nas redes de ensino se transformam em trabalho morto que dominam nossa atividade docente. Ambos os processos dão indícios de uma transformação com consequências drásticas, com inúmeras relações que precisam ser estudadas pormenorizadamente, e por isso tua opinião é valiosa. A educação não está combinada com a produção material, como você e Engels (1998) propunham no Manifesto Comunista, mas subsumida ao capital.

Por certo que a complexa conjuntura atual abarca e impacta a educação de inúmeras formas e eu seria incapaz de lhe oferecer um quadro mais completo, ainda mais nas poucas páginas dessa carta. A mudança na função social da educação massiva se altera em conjunto com o crescente conservadorismo que se intensifica por toda parte, cuja expressão mais radical está no aumento do controle militar, religioso e empresarial da educação formal e não formal. A verdade é que enquanto tramitam no senado e nas câmaras de deputados e vereadores projetos que permitem a atuação legal de tais setores na educação estatal, a atividade destes gestores já tomou conta de diversos pontos estratégicos da estrutura educacional, e logrou alterar suas práticas com impactos na própria natureza das relações educacionais.

Mas educação é apenas um dos atos que ocorrem num cenário distópico. Depois de sucessivas crises e limites que o capital tem encontrado para acumulação, sofremos as consequências de sua busca por saídas e novas frentes para a valorização do valor. O Estado, que é a forma política do capital, como sempre, mas cada vez mais de 
forma desmedida, faz das tripas coração para salvá-lo, com subsídios à produção, fornecimento de crédito abundante e barato, aquisição de títulos financeiros podres, isenções tributárias, entrega de empresas estatais à iniciativa privada etc. De outro lado, o Estado "aperta o cinto" com políticas de "austeridade", em particular com o corte de gastos públicos com direitos sociais, pesquisa, produção científica, crédito para trabalhadores e pequenos produtores. E, no entanto, poderia o Estado retirar-se da gestão das "questões sociais"? Poderia simplesmente reprimir, confinar, cortar direitos e desconectar-se de suas formas de organizar os conflitos que germinam com o aumento exponencial da pobreza e da desigualdade? Trata-se, de outro ponto de vista, de um "Estado Amplo", com gestão empresarial, evangélica e militarizada dos direitos sociais? Ou de uma fase transitória para o fim dos direitos sociais? Por ora, parece que a necessidade de gerir a barbárie pelo controle social em tempos de crise econômica ajustouse à lucratividade desses grupos privados, criando uma situação que fortalece ainda mais o capital em detrimento do trabalho. As questões sociais passam a ser, assim, objetos da intervenção combinada de figuras jurídicas e financeiras públicas e privadas, gerando uma categoria híbrida de controle das "políticas sociais". Na condição de personificações do capital, os interesses desses empresários, os projetos "ultraliberais" e de extrema-direita se misturam e constituem uma unidade.

O processo está em curso e longe de sua conclusão, mas tem avançado na mesma proporção que a voracidade por lucros e a concorrência dessas empresas, disputando fatias do mercado. É evidente que a pavimentação desse caminho é um processo de longa data, no qual diversos tipos de instituições privadas foram ocupando espaços e tomando para si alguns processos educativos ou de gestão da educação estatal. Para tanto, capitalistas não sitiaram, não fizeram uso de força, e nem de nenhum tipo violência contra o Estado. Este último, ao contrário, agiu e tem agido em conjunto, agenciando processos, organizando, facilitando, criando novas formas jurídicas, firmando, 
assim, as famosas "parcerias público-privadas", este eufemismo que encobre essa forma de privatização da educação.

Assim, a situação atual parte de uma realidade muito distinta daquela que você menciona no Capítulo Sexto Inédito de O Capital (MARX, 1978): tanto a presença do trabalho de serviços deixou há tempos de ser insignificante em comparação ao trabalho que se materializa em mercadorias independentes da própria atividade laboral, quanto também os serviços estatais deixaram de se apresentar como uma forma acidental e de pouca relevância para o processo de reprodução capitalista.

A gênese violenta do direito à educação é apagada da história quando ela é considerada apenas do ponto de vista do progresso do modo de vida burguês. A presença totalitária da forma hegemônica da educação organizada pelo Estado faz com que ela pareça natural e essencialmente positiva. Lida a contrapelo, no entanto, a história da expansão do direito à educação se apresenta pela destruição de outras formas de educar e destituição de outras formas de existência não condicionadas pela venda da força de trabalho. O nascimento da educação estatal massiva esteve ligado ao disciplinamento e à contenção das massas de trabalhadores e trabalhadoras expropriadas, e seu desenvolvimento se deu em conjunto com a generalização da força de trabalho como mercadoria. A consolidação e o alargamento das redes educativas sob a forma do direito estatal, por um lado foi decisiva para a constituição da massa de trabalhadores "livres como pássaros", que, além de expropriados dos meios de produção, "por educação, tradição, costume, reconhece as exigências daquele modo de produção como leis naturais evidentes" (MARX, 2013, p. 983). Por outro, competiu para a produção de um tipo específico de inserção na "vida política" na forma da cidadania, a duplicação político-jurídica da existência dos indivíduos, que profundamente desiguais em sua vida prática, assumem no plano jurídico-político uma igualdade formal. Você mostra, nesse seu famoso capítulo sobre a acumulação primitiva (ou original) de O Capital (MARX, 2013), que a violência 
da expropriação "inscrita nos anais da humanidade com traços de sangue e fogo", envolveu o apoio estatal para criar ou direcionar esforços para que um corpo de instituições assistenciais, educativas, repressivas e punitivas atuassem no sentido de conter a vadiagem e quebrar violentamente as resistências de grandes contingentes populacionais expropriados a vender sua força de trabalho à indústria manufatureira nascente. Em cada país ou região este processo ocorreu "com seu colorido" específico, mas contribuiu para o surgimento de investimento estatal em serviços para a população trabalhadora.

De um investimento inicial nas organizações assistenciais e filantrópicas da igreja ou da "sociedade civil" pré-existentes, o Estado passou a profissionalizar os serviços sociais em torno da reprodução de trabalhadores e trabalhadoras. Entre o final do século XIX e todo o século XX houve uma efetiva expansão da educação para a população trabalhadora, assim como de outros direitos sociais - sempre ligados ao trabalho -, criando quadros de serviços e funcionários públicos, com aporte de recursos arrecadados pelo Estado por meio de impostos. O escopo do alargamento dos direitos é mais ou menos significativo em cada país e região, em cada conjuntura, pois além das diferenças dos recursos estatais, o acesso aos direitos está sempre conectado a outras questões políticas. Em grande medida sua expansão passa a ser resposta a conjunturas diversas: de contenção de lutas à respostas a movimentos que reivindicam direitos. Em qualquer um dos casos os direitos sociais na forma de garantias ou serviços gratuitos constituem aparato de reprodução da força de trabalho, na forma de um salário indireto concedido pelo Estado.

No desenvolvimento da grande indústria você relata como as crianças se tornaram a "guloseima" dos industriais, que se deliciavam com a capacidade de explorar trabalho, indiferentemente do sexo e da idade, por conta da simplificação do trabalho que a introdução da maquinaria permitiu. Sua justificativa de defesa de uma intervenção estatal dizia respeito apenas à violência, pois lhe parecia evidente que era preciso preservar jovens e crianças trabalhadoras 
dos efeitos destruidores do sistema capitalista, que explorava indiscriminadamente o trabalho, o que só poderia ser feito pela força social das "leis gerais impostas pelo poder do Estado". Ao mesmo tempo, você considerava necessário que houvesse limites à atuação estatal na organização da vida social de trabalhadoras e trabalhadores, e ao fazer a Crítica do Programa de Gotha (MARX, 2012), indignava-se com o fato de um partido operário defender a "Educação popular universal e igual sob incumbência do Estado". De um lado, o partido defendia propostas utópicas para uma sociedade antagônica, como uma "educação igual para todas as classes"; de outro, apresentava como demanda da classe trabalhadora a educação universal obrigatória, tal qual já havia na Alemanha, e a instrução gratuita, como nos Estados Unidos. O mais importante, no entanto, era que a proposta do partido social-democrata alemão - em tese socialista - deixava-se amoldar pela perspectiva reformista ao defender que a educação popular estivesse a cargo do Estado. "Absolutamente condenável é uma educação popular sob incumbência do Estado", foram as suas palavras. Uma atuação limitada do Estado por meio de alguma lei geral que estabelecesse recursos, qualificação docente e currículo poderia ser aceitável, mas nunca "conferir ao Estado o papel de educador do povo"! Parecia óbvio que o movimento anticapitalista precisaria criar meios de educação autônoma, ligadas ao trabalho produtivo e, ao mesmo tempo, à organização de classe, como você defendera em outros momentos. E no caso da instrução "pública", o movimento deveria cercar a participação do Estado, para manter a educação longe de qualquer influência de governos e igrejas.

E deixamos, pois, que ao longo da história o Estado se tornasse educador do povo. Embora a posição dependente do Brasil tenha feito com que o desenvolvimento capitalista prescindisse da educação e qualificação de trabalhadores e trabalhadoras por muito tempo, aqui, como em muitos outros países, a educação voltada ao povo se desenvolveu sob a forma do direito e, portanto, subordinada ao Estado, sob influência de governos democráticos ou autoritários. 
Mesmo a esquerda em grande medida passou a reivindicar a educação estatal como se ela fosse "coisa nossa", como se o "bem público" fosse de fato um bem comum, como a teoria burguesa admitia. E mais do que isso, não apenas deixamos de colocar limites à atuação do Estado na educação, como depositamos nele toda a responsabilidade de promover a transmissão dos conteúdos escolares, mas também parte importante da socialização de crianças e jovens, e passamos até a reivindicar uma educação integral ao Estado. Passamos a demandar do Estado aquilo que você imaginava que poderia - e deveria - ficar à cargo da organização da classe.

As contradições desse movimento se apresentaram de formas distintas em cada momento da história da divisão social do trabalho, relacionados também à forma e à função que os direitos sociais foram adquirindo, bem como ao papel específico da educação, em particular no que se refere à formação da força de trabalho. Os direitos sociais se converteram em necessidade e, ainda que os serviços sociais estatais se realizem de maneira bastante precária para a maior parte da população, tornaram-se formas de inserção e reprodução da vida social. Não obstante, sua expansão passou ao largo dos objetivos liberais de promover igualdade ou atenuar desigualdades sociais.

No caso da educação escolar, mesmo que não haja universalização - e passamos longe disso nos países periféricos podemos dizer que nunca tivemos tanto acesso ao direito e que, ao mesmo tempo, nunca fomos tão privados de formação. A profusão de ofertas de cursos formais e não formais no período neoliberal deu-se em conjunto com a prática ideológica do "ensinar a ensinar" ou "aprender a aprender", que organismos internacionais passaram a recomendar aos países pobres: a panaceia do acesso à "educação ao longo da vida", para usar outro jargão dessa onda, limitando o ensino de conteúdos em nome de uma suposta "democracia" da socialização e do comportamento "cidadão", transformando o meio num fim em si mesmo, no "direito a ter direitos", como falávamos no fim do século XX. E de fato, na prática se desenvolveu uma "terceira via" entre

$40 \quad$ Direito e educação em estado de exceção 
os extremos que reduziam o socialismo à estatização e o capitalismo à concorrência mercantil, numa defesa que uniu movimentos sociais, empresários, Estado, organizações da sociedade civil, todos lutando pelos "direitos sociais". Todos juntos passaram a defender "instituições republicanas democráticas, não como meio de suprimir dois extremos, capital e trabalho assalariado, mas como meio de atenuar sua contradição e transformá-la em harmonia", como os reformistas socialdemocratas d'O 18 de Brumário (MARX, 2011). O "Estado de Direito", incumbido dos direitos dos trabalhadores e trabalhadoras, passa a organizá-los em conjunto com seus "parceiros", numa harmonia onde todas as partes se beneficiam, com exceção do povo.

Como se tornou natural pensar que "estávamos vencendo" só por estarmos acessando direitos, as formas sociais de realização de tais direitos ficavam escamoteadas. E no entanto, como boa parte dos direitos sociais, tais como a saúde, a educação, o transporte, a assistência social, etc., só podem se realizar, na prática, pela força de trabalho na forma de serviços, este enorme mercado de trabalho também sofre com as ondas de terceirização e de precarização. Sabemos, então, que essas transformações na forma de execução e gestão dos serviços estatais - diga-se de passagem, muito anteriores às aprovações das leis de terceirizações e da Reforma Trabalhista - atingem grande parte da assistência social e da saúde que têm seus centros de referência ou unidades básicas geridas por Organizações Sociais (OS). O direito ao transporte é gerido por uma grande máfia de empresas privadas, e a política habitacional é feita pela parceria entre poder público, empreiteiras e movimentos de moradia transformados em entidades jurídicas. Mesmo a cultura e a educação estão, em grande medida, nas mãos de patronais, bancos e empresários.

A relação entre os sistemas de ensino estatais com essa nova força da indústria do serviço educativo envolve uma variedade muito grande de formas, tamanhos e graus de controle do trabalho educativo. As gestões municipais e estaduais de educação no Brasil têm estabelecido parcerias que vão desde a aquisição de sistemas de ensino 
de empresas da educação, passando por inúmeros tipos de projetos de parcerias com unidades escolares e diretorias de ensino, até a gestão conjunta das políticas e das instituições de ensino. Algumas unidades educativas no Brasil são geridas diretamente por Organizações Sociais da Sociedade Civil, as quais controlam projetos pedagógicos e contratos de trabalho de docentes, e assistimos atualmente à gradativa adesão de tal modalidade de organização na educação básica por estados e municípios brasileiros.

A educação infantil é um caso emblemático, pois nem bem saiu da organização filantrópica e assistencial e passou a ser direito estatal, conquistando certo grau de profissionalização, já vê a transferência de sua gestão para Institutos e Associações Privadas, que é marca do que se tem chamado de "re-filantropilazação". Ao vencer uma licitação ou depois de concorrer a um edital municipal a organização social ganha o direito de realizar serviços terceirizados do modo que lhes parece mais conveniente. $\mathrm{O}$ contrato privado de prestação de serviços aos municípios vale mais do que qualquer lei educativa e, na prática, a "missão" de cada entidade se sobrepõe aos objetivos de uma educação pública, laica e gratuita. Como grande parte das organizações que concorrem são assistenciais ou religiosas, assegura-se a elas, na prática, o direito de explorar trabalho feminino precarizado para realizarem sua doutrinação e desde cedo inserirem crianças nos cultos, rezas, e hábitos culturais de cada entidade privada católica ou evangélica. Os contratos de trabalho são precários e algumas chegam a pagar a metade do salário que uma educadora concursada ganha, numa realidade que atinge grande parte das instituições de educação infantil.

As parcerias entre o público e o privado vão desde as organizações sociais da sociedade civil de pequeno e médio porte, como as que terceirizam serviços da educação infantil, até empresas com enorme poder e capacidade de investimento. A gigantesca Fundação Lemann, por exemplo, oferece serviços de consultoria e gestão educacional de municípios inteiros para atuar nas secretarias de educação, diretorias e escolas. Atualmente tem contrato em vinte e duas cidades brasileiras, 
e suas atividades são desenvolvidas por empresas subcontratadas pela Fundação, que por sua vez podem fazer novas parcerias com fundações e associações "sem fins lucrativos" para desenvolver projetos com escolas e comunidade. Lemann, empresário mais rico do Brasil, investe em cerveja, ketchup e hambúrgueres como investe em educação, até porque, segundo ele mesmo, seu "negócio não é cerveja, nem hambúrguer ou ketchup, é gente" ${ }^{2}$. Além de investir na expansão da presença de grandes marcas imperialistas que contratam força de trabalho brasileira, também investe em gente quando financia organizações ou protestos de movimentos conservadores, e mesmo proto-fascistas.

Poderia dizer que os governos, eleitos ou não, estão surfando na onda do refluxo das últimas greves docentes, e sobretudo do movimento secundarista de ocupação das escolas de 2015 e 2016. Durante os protestos, uma ação combinada: enquanto o Estado reprimia violentamente os estudantes, parte do empresariado aplaudia o "protagonismo juvenil", não só porque a imagem democrática jogava a seu favor, mas também porque era preciso que a "sociedade civil" demostrasse que apoia a mudança na educação. Na sequência a reação foi traçada linha à linha pela aliança entre Estado e Fundações de empresas e bancos, que incorporou cada um dos elementos da pauta estudantil na sua semântica e tática de atuação. Como resposta às reivindicações, do controle ao grêmio estudantil aos métodos pedagógicos empreendedores que ensinam a submissão travestida de uma espécie de "gestão do futuro por metas" pela incorporação dos "projetos de vida" aos currículos, o maior ganho, sem dúvida, é conseguir propagandear e implementar a Reforma do Ensino Médio, que está sendo construída há mais de uma década pelos empresários em conluio com diversos governos, como se redução de conteúdos fosse "flexibilização de currículo", como se desigualdade educacional

${ }^{2}$ Https://revistapegn.globo.com/Empreendedorismo/noticia/2018/01/jorge-paulo-lem ann-nosso-negocio-nao-e-cerveja-nem-hamburguer-ou-ketchup-e-gente.html. Consultado em 23.08.2018. 
fosse diversificação. O fato é que em São Paulo, e imagino que no Brasil todo, a reação empresarial foi digna de uma tática de guerrilha, com uso de um "trabalho de base" às avessas com oferecimento - muitas vezes gratuito ou comprado pelas secretarias como serviço - de "capacitações", "formações", "oficinas" para estudantes, docentes e direção escolar, voltadas para a ideologia do empreendedorismo e da competição.

A Króton - maior e mais lucrativa indústria de serviços e investimentos educativos -, por exemplo, depois das ocupações ofereceu serviços gratuitos e firmou contrato com a Secretaria Estadual de São Paulo, por meio da Aliança Brasileira pela Educação (ABE). Segundo seus informativos disponíveis na internet essa aliança "se fundamenta na articulação de parcerias entre os três setores Governo, Empresas e Fundações, para que as instituições se integrem e somem forças na direção desse nobre desafio - melhorar a educação pública brasileira - bandeira comum de toda sociedade". Atuando diretamente com a formação de "lideranças em gestão educacional", busca "capacitar" diretores e diretoras de escolas públicas para que estes saibam fazer parcerias com projetos do terceiro setor.

O processo de fusões e aquisições de empresas privadas de educação gera uma concentração tão grande de capitais, que torna viável e rentável um grande investimento nos meios de trabalho educativo, seja pela digitalização de conteúdos e produção de materiais para os processos de ensino, quanto pelo desenvolvimento de aplicativos de gestão e diversas formas de controle de trabalho. Nas redes públicas, tão sucateadas e com pouca infraestrutura, tornouse comum o relato de trabalhadores ou estudantes de que tablets, televisões, lousas digitais e instalação de internet são doados por empresários, que depois vendem a essas escolas sistemas de ensino, com pacotes educativos, softwares, aplicativos de gestão, etc. A mesma Króton, por exemplo, que gera notícias diariamente com suas fusões, criação de holdings, emissão de bilhões de reais em debêntures para novas aquisições, anunciou recentemente que, para investir na criação 
e distribuição de tecnologias educacionais, será uma das principais parceiras do "Itaú Cubo", uma "incubadora de startups" criada pelo banco Itaú.

$\mathrm{O}$ que quero mostrar com estes exemplos, que poderiam se multiplicar, é que a forma social da educação básica, que deixamos a cargo do Estado sob a forma do direito público, está se transformando mediante as combinações entre Estado e mercado, ambos agindo em defesa do "direito à educação". Se nas últimas décadas as reformas educativas buscaram ajustar o serviço estatal à lógica de gestão empresarial por uma espécie de simulacro de relações que mimetizavam as relações mercantis, parece-me que a reforma do ensino médio em curso tende a romper o último enclave para a subsunção mais completa da educação estatal ao capital, alterando radicalmente o processo de trabalho educativo, e detonando os poros abertos de uma atividade ainda não completamente controlada. Ao subordinar o trabalho educativo - da gestão aos conteúdos pedagógicos - ela subordina também a formação de trabalhadores e trabalhadoras aos ditames de bancos e grandes conglomerados empresariais organizados em "movimentos" como o "Todos Pela Educação". Desse modo, fazse imperioso refletir sobre o papel da política institucional quando a agenda de "reformas" e mudanças estabelecidas por estes empresários está sendo seguida à risca pelos governos da última década.

Do ponto de vista econômico, o Estado não passa a fazer, ele mesmo, um investimento produtivo quando canaliza os impostos arrecadados para as mãos de capitalistas que organizam e terceirizam trabalhos sociais precarizados? $O$ trabalho comandado por esses capitalistas torna-se produtivo (portanto produtor de mais-valia) mesmo que a educação permaneça sendo oferecida gratuitamente? O que essa forma híbrida de gestão de controle dos direitos sociais significa do ponto de vista da exploração deste imenso mercado de trabalho?

Além do ganho econômico, os ganhos políticos do capital ao terceirizar os trabalhos já são bastante conhecidos: com a diversificação 
de prestadoras de serviços, multiplicam-se os patrões, fragmenta-se e se dificulta a organização das lutas em torno das condições de trabalho. A concorrência mercantil entre as prestadoras de serviços implica numa constante busca por redução de custos da força de trabalho e por ampliação do tempo de trabalho excedente, na combinação entre a extração de mais-valia absoluta e de relativa. Com algumas das tecnologias que estão sendo mobilizadas no interior da escola tendese a ampliar a subsunção real do trabalho ao capital, que no caso dos trabalhos "imateriais", por sua natureza concreta, impunham limites a esta subsunção, conforme a tua análise em Capítulo Sexto Inédito de O Capital (MARX, 1978). Assim como nos processos chamados de "uberização", a tecnologia tem sido inserida na gestão e na avaliação constante do trabalho. Com isso, não se abre mão do trabalho simples, como ocorreria com o uso de um automóvel autônomo, mas submetese o trabalho simples ao complexo controle de grandes conglomerados empresariais, pelo intermédio de aplicativos que fazem a gestão e selam os contratos de trabalho intermitente.

Ainda que a automatização do trabalho docente possa ser vislumbrada no horizonte, e mesmo diante do aumento do emprego de meios tecnológicos e digitais, em particular no ensino à distância, a sua universalização parece distante, em função da necessidade social de confinamento e controle, sobretudo da pobreza. Se há ainda limites para a substituição do trabalho de ensinar por máquinas, o mesmo não ocorre com a gestão do trabalho educativo, e aqui a introdução da tecnologia como mecanismos de organização, controle e avaliação contínua da atividade educativa, já compete para simplificar o trabalho docente e expropriá-lo de seu conteúdo.

E o que dizer dos ganhos políticos de controlar deste modo a educação de jovens trabalhadores? Na verdade, o que parece é que o sistema de ensino estatal, até hoje marcado por certa homogeneidade, nos contornos de direito universal e organizado diretamente pelo Estado, tende a se diversificar por meio da terceirização da gestão, em meio às disputas entre grupos empresariais por estes verdadeiros

46 Direito e educação em estado de exceção 
nichos de mercado que se tornaram as redes de ensino públicas e privadas, no bojo dos direitos focais, voltado para "públicos-alvo" específicos. Nesse sentido, o acesso ao direito à educação tenderá a estar ainda mais subordinado à desigualdade de condições oferecidas pelas empresas prestadoras de serviços, no processo de formação da força de trabalho que elas mesmas irão explorar.

Parece-me que, diante das palavras de ordem das lutas por direitos, as respostas estatais hoje caminham simbioticamente unidas ao capital, fortalecendo-o ainda mais. Deste modo, esse tipo de reivindicação, desacompanhada de alternativas práticas contrahegemônicas, não servirão para arrancar a educação de trabalhadores e trabalhadoras das mãos de seus adversários. Ao contrário, a "estridência democrática" e a "credulidade servil ao Estado", que andam de mãos dadas, e que hoje acometem importante parcela da esquerda brasileira, não tendem a bloquear a crítica teórica e prática ao capital, com efeitos avassaladores, assim como ocorria nos tempos do Programa de Gotha (MARX, 2012, p. 46)? Não se aprofunda a posição invertida de um Estado que "necessita receber do povo uma educação muito rigorosa"?

A intensificação da barbárie também se amplia com a gestão dos direitos sociais dos atingidos pela infame ordem do capitalismo atual sob controle de quem personifica o capital. E assim, mesmo do ponto de vista de uma noção ideológica de progresso, me parece que nada poderia justificar que se veja tanto retrocesso na perda de direitos e nenhum retrocesso na redução de nosso horizonte prático à luta por direitos.

Enfim, meu caro Marx, se é verdade que a tenacidade de sua teoria crítica e revolucionária se prova pela permanência dela entre nós; é verdade também que sofremos os ônus destes tempos de devastação de qualquer expectativa revolucionária concreta. Esse tipo de pobreza de experiência nos afasta da produção de imagens dialéticas dos "momentos de perigo", dos quais falava Walter Benjamin (2005), imagens que pudessem expressar as contradições sociais sem tantas 
camadas de neblina ideológica. Não obstante, aprendemos contigo que é o exercício constante de enfrentamentos ao capital, em conexão com as lutas do passado, que servirá de antessala para a necessária recriação de uma estratégia e teoria revolucionária, à altura do contexto.

Já abusei de sua paciência, e detenho-me por aqui. Não sem antes dizer que por meio de teus escritos e de tua prática, fomos escolados contra um espanto aterrador em relação às atuais tendências da educação no Brasil. Trata-se de transformações assentadas sobre tendências da própria forma social do capital, e do Estado como sua expressão política, que tendem a dominar tudo, a penetrar todas as relações sociais, como você elucidou. Tais tendências se afirmam violentamente num contexto de crise, em que o motor da acumulação de capital perde força, e que a classe trabalhadora acumula derrotas. Não obstante, teu pensamento nos deixa igualmente imunes à paralisia, pois revela os limites do impulso totalitário do capital, e demonstra que, diante da barbárie capitalista, só resta nos levantarmos, sacudirmos a poeira, compreendermos os motivos da queda, e nos fortalecermos, crítica e praticamente, na construção da ruptura revolucionária.

É preciso construir um verdadeiro estado de exceção para frear o ritmo alucinante deste estado de exceção permanente.

Seguimos, em sua companhia.

Grande abraço, com saudações revolucionárias!

Carolina Catini 


\section{Referências bibliográficas}

BENJAMIN, W. “Teses sobre o conceito de história”. IN: Löwy, M. Walter Benjamin: aviso de incêndio. São Paulo, Boitempo, 2005.

MARX, Karl e ENGELS, F. Manifesto do partido Comunista 150 anos depois. COUTINHO (et al), Daniel Aarão Reis Filho (org.). Rio de Janeiro: Contraponto, São Paulo: Fundação Perseu Abramo, 1998.

MARX, Karl. O Capital. Crítica à economia política. Livro I. São Paulo: Boitempo, 2013.

- O Capital. Capitulo Sexto Inédito. São Paulo, Ed. Ciências Humanas, 1978.

. Crítica do Programa de Gotha. São Paulo: Boitempo, 2012.

. O 18 Brumário de Napoleão Bonaparte. São Paulo, Boitempo, 2011. 
